\title{
Clinical, Biochemical and Molecular Characteristics of Fifteen Patients with Mucopolysaccharidosis Type II in Western Turkey
}

\author{
(1) Havva Yazıcı1, (1) Ebru Canda1, (1) Esra Er1, (1) Sema Kalkan Uçar1, (1) Hüseyin Onay2, \\ (1) Ferda Özkınay2, (1) Mahmut Çoker1 \\ ${ }^{1}$ Ege University Faculty of Medicine, Department of Pediatric, Division of Pediatrics Metabolism and Nutrition, Izmir, Turkey \\ 2Ege University Faculty of Medicine, Department of Genetics, Izmir, Turkey
}

\begin{abstract}
Aim: Mucopolysaccharidosis Type II (MPS II, Hunter syndrome, OMIM 309900) is a rare X-linked lysosomal storage disease due to a deficiency of the iduronate-2-sulfatase (IDS) enzyme, which is one of the degradative enzymes of mucopolysaccharides. The purpose of this study is to present the clinical, biochemical and molecular characteristics of fifteen patients with MPS II in western Turkey.

Materials and Methods: A retrospective study was carried out on fifteen patients with MPS II who were followed up by Ege University Faculty of Medicine, Unit of Pediatric Metabolic Diseases and Nutrition between October 2004 and September 2017.

Results: The age range of the patients enrolled in the study was between 11 months and 318 months at the time of diagnosis. The most common symptom was coarse face. On physical examination, all of the patients presented with coarse face, macrocephaly and organomegaly. Except for one patient, all other were severe phenotype. IDS activity was significantly decreased in all patients in whom enzyme analysis was performed. In this study, one novel mutation was described.

Conclusion: This is the first study on the clinical and molecular characterization of Turkish MPS II patients. The majority of the patients had neurologic involvement with different degrees of severity. The molecular analysis revealed one novel mutation.

Key words: Mucopolysaccharidosis Type II, Hunter syndrome, lysosomal storage disease, Turkey
\end{abstract}

\section{Introduction}

Mucopolysaccharidosis Type II (MPS II, Hunter syndrome, OMIM 309900) is one of the seven types of MPS I, II, III, IV, $\mathrm{VI}, \mathrm{VII}, \mathrm{IX}$. This is a rare $\mathrm{X}$-linked lysosomal storage disease due to a deficiency of the iduronate-2-sulfatase (IDS) enzyme, which is first degradative enzyme of mucopolysaccharides [now preferentially termed glycosaminoglycans, (GAGs)] dermatan sulfate and heparan sulfate. GAGs are essential constituents of connective tissue including cornea, cartilage, cardiac valve and vessel walls (Table I) (1). Partially digested dermatan sulfate and heparan sulfate accumulates and leads to multisystemic alterations including the skeleton, internal organs and central nervous system. The clinical characteristics of MPS II are macrocephaly, coarse face, hepatosplenomegaly, hernia, stiff joints, recurrent upper airway infections or otitis media, hearing loss, cardiac valve disease and/or cardiomyopathy and neurologic impairment. The IDS gene is located on Xq28 and contains 9 exons. The gold standard for diagnosis of MPS II in a male proband is reduced levels of IDS enzyme activity in fibroblasts, plasma or white cells and then diagnosis can be confirmed by means of IDS gene analysis. On exceptional occasions, heterozygous females present symptoms of MPS II. X inactivation, which 
is inactivation of normal paternally inherited $X$ chromosome and expression of the maternally inherited $X$ chromosome, can be the explanation for this issue $(2,3)$. The IDS gene has three categories of alteration; large gene deletions, rearrangements and small gene deletions. More than 550 different mutations have been identified in the IDS gene to date, according to the Human Genome Mutation Database $\left(\mathrm{HGMD}^{\circledR}\right.$ Professional 2016.2, www.hgmd.cf.ac. uk). Most of these are point mutations. IDS gene analysis is beneficial in diagnosing patients with unusual phenotypes and identifying genotype-phenotype correlations and it is also the only reliable way to define female carriers of the disease, which is a crucial factor in family planning (4). MPS II has multisystemic manifestations with variety in both the age of disease onset and rate of progression. Non-specific signs and symptoms that are similar to common childhood diseases and a lack of disease awareness cause delayed diagnosis (5). Although corneal clouding is not a typical feature of MPS II, it should not be forgotten. Two forms of the disease have been described. The most common form is often labelled as "early progressive" and manifests primarily with a combination of progressive cognitive deterioration and other multisystemic involvement. This form usually leads to death by the end of the second decade. The more infrequent form is often labelled as "slowly progressive", without or with a minimally affected central nervous system (6). The disease onset for the severe form is 12-18 months of age and for the attenuated form is $2-4$ years of age (7).

Two main therapies have been reported for MPS II patients: The first one is idursulfase as an enzyme replacement therapy (ERT) which is a recombinant form of human IDS. This was approved in 2006 in individuals with the slowly progressing form of the disease. ERT has been shown to improve somatic symptoms, but the results with regard to cognitive functioning have been poor as idursulfase does not cross the blood-brain barrier (8). Hematopoietic stem-cell transplantation (HSCT) is reported as the other therapy. To date, only a few studies have examined the longterm outcomes of HSCT in patients with MPS II $(9,10)$. HSCT can preserve neurocognition when performed early in the course of the disease. The need for early identification makes Hunter disease a candidate for new-born screening (NBS). Additionally, if NBS becomes widespread for MPS II, much milder presentations will be identified (11). Since there are no studies in Turkey on MPS II patients, the objective of this study is to present the genetic and clinical characteristics of patients in Western Turkey with Hunter syndrome.

\section{Materials and Methods}

A retrospective study was carried out on 15 patients with MPS II (from 13 families) and who were followed up by the Ege University Faculty of Medicine, Unit of Pediatric Metabolic Diseases and Nutrition, between October 2004 and September 2017. The data of patients including demographic, clinical, biochemical, radiological and mutation analyses were collected from their medical records. Diagnosis of MPS II was carried out by a detection of decreased levels of IDS enzyme activity in fibroblasts, plasma or white cells or by molecular genetic analysis. None of the patients were screened at birth for MPS II.

\section{Statistical Analysis}

The quantitative patient characteristics are summarized by means and standard deviations (SD). The qualitative characteristics such as general appearance and organ complications are presented as a frequency distribution.

\section{Results}

We collected data from 15 patients belonging to 13 families followed up by the Ege University Faculty of Medicine, Unit of Pediatric Metabolic Diseases and Nutrition. There were four patients in this study from two separate families. All patients were male. The patients age was between 11 months and 318 months at the time of diagnosis with a mean of 62 months and a median of 52 months. The youngest age at the diagnosis was eleven months and the oldest was 318 months. At the time of the study, the mean age of the living patients was 88.1 (SD 53.8) months. According to the birth weight data, two patients were "macrosomic", which literally means "big bodied", (defined by the American College of Obstetricians and Gynaecologists, as birth-weight $>4000 \mathrm{~g}$ or $>4500 \mathrm{~g}$ irrespective of gestational age). Another two patients were large for gestational age (LGA) (defined as a weight, length or head circumference that lies above the $90^{\text {th }}$ percentile for gestational age). The clinical characterizations of the patients are summarized in

Table I. Pathological glycosaminoglycans in different mucopolysaccharidosis

\begin{tabular}{|c|c|c|c|c|c|c|c|c|c|}
\hline & \multirow{2}{*}{$\begin{array}{l}\overline{\text { তू }} \\
\text { 흘 }\end{array}$} & \multicolumn{7}{|c|}{ Mucopolysaccharidosis } & \multirow{2}{*}{ Typical clinical findings, affected organ systems } \\
\hline & & I & II & III & IV & VI & VII & IX & \\
\hline Chondroitin sulphate & + & & & & $(+)$ & & + & ++ & \\
\hline Dermatan sulphate & & ++ & ++ & & & ++ & $n-+$ & & Skeleton + internal organs \\
\hline Heparan sulphate & & + & + & + & & & $n-+$ & & Intellectual disability \\
\hline Keratan sulphate & & & & & + & & & & Skeleton \\
\hline
\end{tabular}

++: Prominent feature, +: Often present, $(+)$ : Sometimes present 
Table II. The height of the patients was variable depending on their age (between $+1.88 \mathrm{SD}$ and $-7.5 \mathrm{SD}$ ); under five years, $5-10$ years and $>10$ years, the mean heights were $+0.07 \pm 1.8$ $\mathrm{SD},-2.48 \pm 2.05 \mathrm{SD}$ and $-3.84 \pm 2.58 \mathrm{SD}$ respectively. Figure 1 presents the main symptoms of the study group; the most common symptom was coarse face $(100 \%)$, and the others, in order of prevalence, were developmental delay (93\%), joint stiffness $(60 \%)$, recurrent upper airway infections $(47 \%)$, hernia (33\%), convulsion (27\%) and recurrent ear infections $(20 \%)$. Coarse face, macrocephaly and organomegaly were the main findings detected by physical examination (Figure

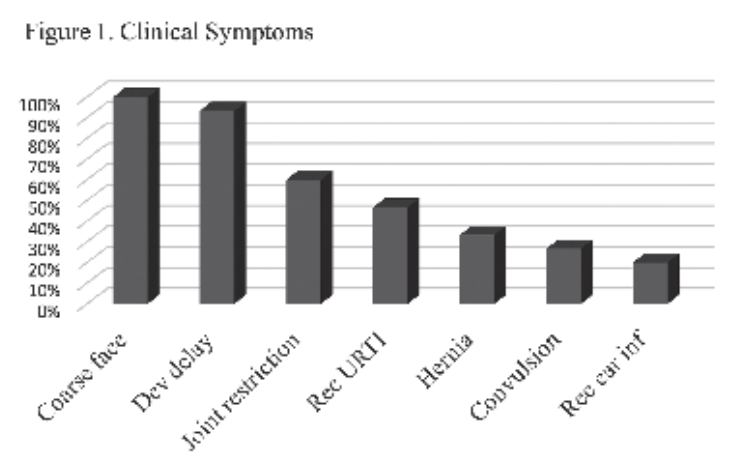

Figure 1. Clinical symptoms

Dev: Development, URTI: Upper respiratory tract infection, Rec: Recurrent, Inf: Infection

\begin{tabular}{|l|l|l|l|l|}
\hline \multicolumn{5}{|l}{ Table III. Iduronate-2 sulfatase activity } \\
\hline Patient & $\begin{array}{l}\text { Enzyme } \\
\text { activity }\end{array}$ & $\begin{array}{l}\text { Normal } \\
\text { range }\end{array}$ & Unit of measure & $\begin{array}{l}\text { Sample } \\
\text { type }\end{array}$ \\
\hline H2 & 0 & $494-1113$ & $\mathrm{nmol} / \mathrm{mL} / 4 \mathrm{~h}$ & Plasma \\
\hline H3 & 0.37 & $494-1113$ & $\mathrm{nmol} / \mathrm{mL}$ & Plasma \\
\hline H4 & 0.5 & $32-65$ & $\mathrm{nmol} / 4 \mathrm{~h} / \mathrm{mg}$ protein & Plasma \\
\hline H6 & 0 & $35-110$ & $\mathrm{nmol} / 4 \mathrm{~h} / \mathrm{mg}$ protein & Fibroblast \\
\hline H7 & 0.62 & $28.2 \pm 9.75$ & $\mathrm{nmol} / 4 \mathrm{~h} / \mathrm{mg}$ protein & Plasma \\
\hline H8 & 0 & $494-1113$ & $\mathrm{nmol} / \mathrm{mL} / 4 \mathrm{~h}$ & Plasma \\
\hline H8S & 0 & $494-1113$ & $\mathrm{nmol} / \mathrm{mL} / 4 \mathrm{~h}$ & Plasma \\
\hline H10 & 0 & $494-1113$ & $\mathrm{nmol} / \mathrm{mL} / 4 \mathrm{~h}$ & Plasma \\
\hline H10S & 0 & $494-1113$ & $\mathrm{nmol} / \mathrm{mL} / 4 \mathrm{~h}$ & Plasma \\
\hline H13 & 0 & $494-1113$ & $\mathrm{nmol} / \mathrm{mL} / 4 \mathrm{~h}$ & Plasma \\
\hline & & Control & & \\
\hline H5 & 0 & $\begin{array}{l}\text { PC: } 0.91-\mathrm{NC:} \\
0.74\end{array}$ & $\mathrm{nmol} / \mathrm{mg} / \mathrm{mL}$ & Plasma \\
\hline H9 & 0.06 & $\begin{array}{l}\mathrm{NC1:32.33-} \\
\mathrm{NC2:31.37}\end{array}$ & $\mathrm{nmol} / 4 \mathrm{~h} / \mathrm{mg}$ protein & Plasma \\
\hline H11 & 0.71 & $\begin{array}{l}\mathrm{NC1}: 42.4- \\
\mathrm{NC2:} 47.4\end{array}$ & $\mathrm{nmol} / 4 \mathrm{~h} / \mathrm{mg}$ protein & Plasma \\
\hline
\end{tabular}

H: Hunter, NC: Normal control, PC: Positive control, S: Sibling

\begin{tabular}{|c|c|c|c|c|c|c|c|c|c|c|c|}
\hline 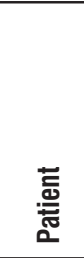 & 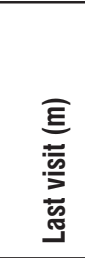 & 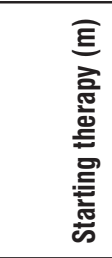 & 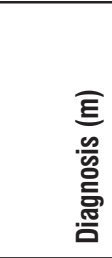 & $\begin{array}{l}\text { छ } \\
\overline{\bar{\Xi}} \\
\text { 产 }\end{array}$ & 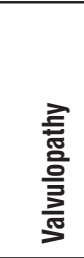 & 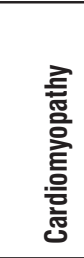 & 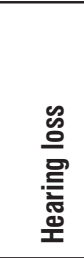 & 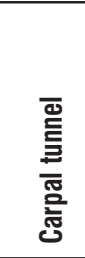 & 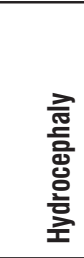 & 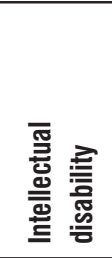 & 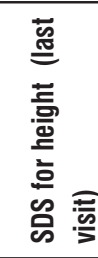 \\
\hline $\mathrm{H} 1$ & 140 & No & 12 & Ex & + & + & & & + & + & \\
\hline $\mathrm{H} 2$ & 127 & No & 53 & Ex & & & & & + & + & -0.98 \\
\hline $\mathrm{H} 3$ & 353 & 354 & 318 & Ex & + & - & + & + & - & - & -4.98 \\
\hline $\mathrm{H} 4$ & 160 & 95 & 64 & Ex (159) & + & + & + & + & + & + & -5.36 \\
\hline $\mathrm{H} 5$ & 180 & 99 & 52 & Ex (180) & + & + & + & + & - & + & -3.11 \\
\hline $\mathrm{H} 6$ & 179 & 82 & 24 & Alive (178) & + & - & + & + & - & + & -7.50 \\
\hline $\mathrm{H} 7$ & 112 & 66 & 57 & Ex (119) & + & - & + & + & - & + & -3.42 \\
\hline H8 & 80 & No & 68 & Ex & + & + & & + & + & + & -4.92 \\
\hline $\mathrm{H} 8 \mathrm{~S}$ & 39 & 72 & 50 & Alive (126) & + & + & & - & - & + & -2.50 \\
\hline H9 & 134 & 53 & 52 & Alive (133) & + & - & + & + & + & + & -1.10 \\
\hline $\mathrm{H} 10$ & 55 & 33 & 30 & Alive (54) & - & - & - & - & - & + & -0.08 \\
\hline H10S & 89 & 66 & 69 & Alive (88) & + & - & + & + & + & + & -0.58 \\
\hline H11 & 37 & 24 & 20 & Alive (36) & + & - & + & - & - & + & 1.00 \\
\hline $\mathrm{H} 12$ & 21 & 13 & 11 & Alive (21) & - & + & + & - & + & + & 1.88 \\
\hline $\mathrm{H} 13$ & 70 & 1 & 62 & Alive (69) & & & & & - & + & -1.00 \\
\hline
\end{tabular}


1). Apart from $\mathrm{H} 3$, all of the patients presented neurologic involvement, mild to severe intellectual disability. $\mathrm{H} 3$ had no intellectual disability. Among follow up and living patients, five patients are able to walk without support and two patients are wheelchair-bound. Convulsion was noted in four patients $4 / 15$ (26\%). Cardiac involvement manifested at variable grades of valvulopathy $(11 / 13-84 \%)$ and left ventricular hypertrophy (6/13-46\%). In 11 patients with valvulopathy; mitral valve involvement was 90\% (10/11), aortic valve involvement $63 \%$ and tricuspid valve involvement was $36 \%$ (4/11). On bone survey, dysostosis multiplex was noted in $12 / 12$ patients. Hydrocephaly was noted in $7 / 15$ patients on cranial imaging, and three of the seven patients with hydrocephaly had a shunt procedure. Carpal Tunnel syndrome was observed in eight patients on electromyography (8/12$66 \%)$. Three patients had broad Mongolian spot on physical examination. Three patients never received ERT and none of patients had no HSCT. ERT was started at the age of $83 \pm 76$ months (limits: 11-319). Urinary GAG was elevated in all patients and increased dermatan sulfate and heparan sulfate was seen in GAG electrophoresis of 9 patients. IDS activity was significantly diminished in all patients in whom enzyme analysis was performed (Table III). Minor genetic defects were identified by molecular analysis (Table IV) in all patients in whom IDS gene analysis was performed, one of them was nonsense and the others were missense. One novel mutation was described.

\section{Discussion}

This is the first study on the clinical and gene mutation characterizations of Turkish MPS II patients. According to the birth weight data, two patients were macrosomic and another two patients were LGA. Previous studies have analysed birth parameters in patients with MPS II and mean birth weight has been reported to be slightly higher in MPS II patients than in those of the general population (15-19). Recently, a new large study from The Hunter Outcome Survey (HOS) also shows that birth weight is not associated with disease severity, in contrast to other previous studies (20). The age of admission or referral to a metabolic centre may be delayed. The need for early identification of mild presentations makes Hunter disease a candidate for NBS (11). The second most common symptom was developmental delay $(93 \%)$, parallel to this data $14 / 15$ patients had the severe form of the disease, which is consistent with recent studies (21-23). A total of 13/15 patients were assessed with echocardiography and cardiac involvement was detected in 12 of these patients. This data is compatible with the reports from HOS wherein the prevalence of cardiac presentation is high and valvular disease is the most common involvement (24-27). Three patients had broad Mongolian spot on physical examination. A clinical link between Mongolian spots and MPS II and other lysosomal storage diseases has already been reported in the literature (28-30). Mongolian spots may be one of the key factors in the early diagnosis of MPS II. IDS activity was significantly diminished in all patients in whom enzyme analysis was performed. Residual enzyme activity showed no predictive value (31).

\section{Study Limitations}

Limitations of the present study are that the enzyme levels were not measured for all of the patients and the molecular analysis of all patients were not taken into consideration.

\section{Conclusions}

This is the first study on the clinical and gene mutation characterization of Turkish MPS II patients. The clinical characteristics of MPS II in this case series were in agreement with what has been reported in that the age of diagnosis is much delayed despite an earlier onset of symptoms. Most of the patients had neurologic findings with different grades of severity. The molecular analysis revealed one novel mutation.

\section{Ethics}

Informed Consent: Informed consent was obtained.

Peer-review: Externally peer-reviewed.

\section{Authorship Contributions}

Surgical and Medical Practices: H.Y., E.C., H.O., F.Ö., Concept: S.K.U., Design: M.Ç., Data Collection and Processing: E.C., Analysis and Interpretation: H.Y., Literature Search: E.E., Writing: H.Y.

Conflict of Interest: No conflict of interest was declared by the authors.

Financial Disclosure: The authors declare that this study received no financial support.

Table IV. Mutation analysis of IDS gene

\begin{tabular}{|l|l|l|l|l|l|l|}
\hline Patient & Mutation & Consequence & Location & Phenotype & Status & Reference \\
\hline H3 & c.322T>G & p.Y108D & Exon 3 & Mild & Novel & - \\
\hline H4 & c.262C>T & p.R88C & Exon 3 & Severe & Published & Rathmann et al., (12) \\
\hline H6 & c.262C>T & p.R88C & Exon 3 & Severe & Published & Rathmann et al., (12) \\
\hline H9 & c.672G $>$ A & p.G224E & Exon 5 & Severe & Published & Karsten et al., (13) \\
\hline H11 & c.263G $>$ A & p.R88H & Exon 3 & Severe & Published & Rathmann et al., (12) \\
\hline H12 & c.162T>G & p.Y54X & Exon 2 & Severe & Published & Mutesa et al., (14) \\
\hline
\end{tabular}




\section{References}

1. Guillén-Navarro E, Domingo-Jiménez MR, Alcalde-Martín C, et al. Clinical manifestations in female carriers of mucopolysaccharidosis type II: a Spanish cross-sectional study Orphanet J Rare Dis 2013;8:92.

2. Jurecka A, Krumina Z, Żuber Z, et al. Mucopolysaccharidosis type II in females and response to enzyme replacement therapy. Am J Med Genet A 2012;158:450-4.

3. Parenti G and Wraith EJ. (2014) The Mucopolysaccharidoses. In: Blau N, Duran M, Gibson KM, Dionisi-Vici C (eds) Physician's Guide to the Diagnosis, Treatment, and Follow-Up of Inherited Metabolic Diseases, Springer, Heidelberg, New York, Dordrecht, London, pp 449-64.

4. Scarpa M. Mucopolysaccharidosis Type II. In: Adam MP, Ardinger HH, Pagon RA, Wallace SE, Bean LJH, Mefford HC, Stephens K, Amemiya A, Ledbetter N (eds) GeneReviews $®$ [Internet]. Seattle (WA): University of Washington, Seattle; 1993-2017. 2007 Nov 6 [updated 2015 Mar 26].

5. Burton BK, Giugliani R. Diagnosing Hunter syndrome in pediatric practice: practical considerations and common pitfalls. Eur J Pediatr 2012;171:631-9.

6. Jones S, Wijburg F. Mucopolysaccharidoses, Oligosaccharidoses and Sialic Acid Disorders. In: Saudubray JM, van den Berghe G, Walter JH (eds) Inborn metabolic diseases, diagnosis and treatment, 6th edn. Springer, Heidelgerg, (2016) pp 577-88.

7. Wraith JE, Scarpa M, Beck M, et al. Mucopolysaccharidosis type II (Hunter syndrome): a clinical review and recommendations for treatment in the era of enzyme replacement therapy. Eur J Pediatr 2008;167:267-77. Epub 2007 Nov 23.

8. Muenzer J, Giugliani R, Scarpa M, et al. Clinical outcomes in idursulfase-treated patients with mucopolysaccharidosis type II: 3-year data from the hunter outcome survey (HOS). Orphanet $J$ Rare Dis 2017;12:161

9. Kubaski $F$, Yabe $H$, Suzuki $Y$, et al. Hematopoietic Stem Cell Transplantation for Patients with Mucopolysaccharidosis II. Biol Blood Marrow Transplant 2017;23:1795-803.

10. Barth $A L$, de Magalhães TSPC, Reis $A B R$, et al. Early hematopoietic stem cell transplantation in a patient with severe mucopolysaccharidosis II: A 7 years follow-up. Mol Genet Metab Rep 2017;12:62-68.

11. Ruijter GJ, Goudriaan DA, Boer AM, et al. Newbornscreening for hunter disease: a small scale feasibility study. JIMD Rep 2014;14:23-7

12. Rathmann $M$, Bunge $S$, Beck $M$, et al. Mucopolysaccharidosis type II (Hunter syndrome): mutation "hot spots" in the iduronate2-sulfatase gene. Am J Hum Genet 1996;59:1202-9.

13. Karsten $\mathrm{S}$, Voskoboeva E, Tishkanina $\mathrm{S}$, et al. Mutational spectrum of the iduronate-2-sulfatase (IDS) gene in 36 unrelated Russian MPS II patients. Hum Genet 1998;103:732-5.

14. Mutesa L, Muganga N, Lissens $W$, et al. Molecular analysis in two siblings African patients with severe form of Hunter
Syndrome: identification of a novel (p.Y54X) nonsense mutation. J Trop Pediatr 2007:53:434-7.

15. Schwartz IV, Ribeiro MG, Mota JG, et al. A clinical study of 77 patients with mucopolysaccharidosis type II. Acta Paediatr 2007:96:63-70.

16. Rozdzynska A, Tylki-Szymanska A, Jurecka A, Cieslik J. Growth pattern and growth prediction of body height in children with mucopolysaccharidosis type II. Acta Paediatr 2011;100:456-60.

17. Patel P, Suzuki $Y$, Maeda M, et al. Growth charts for patients with Hunter syndrome. Mol Genet Metab Rep 2014;1:5-18.

18. Rozdzynska-Swiatkowska A, Jurecka A, Cieslik J, Tylki-Szymanska A. Growth patterns in children with mucopolysaccharidosis I and II. World J Pediatr 2015;11:226-31.

19. Rozdzynska-Swiatkowska A, Jurecka A, Zuber Z, Tylki-Szymanska A. Can macrosomia or large for gestational age be predictive of mucopolysaccharidosis type I, II and VI. Pediatr Neonatol 2016;57:181-7.

20. Bodamer O, Scarpa M, Hung C, Pulles T, Giugliani R. Birth weight in patients with mucopolysaccharidosis type II: data from the Hunter Outcome Survey (HOS). Mol Genet Metab Rep 2017;11:62-4.

21. Reboun M, Rybova J, Dobrovolny R, et al. X-chromosome inactivation analysis in different cell types and induced pluripotent stem cells elucidates the disease mechanism in a rare case of mucopolysaccharidosistype II in a female. Folia Biol (Praha) 2016;62:82-9.

22. Martin $R$, Beck $M$, Eng $C$, et al. Recognition and diagnosis of mucopolysaccharidosis II (Hunter syndrome). Pediatrics 2008;121:e377-86.

23. Beck M. Mucopolysaccharidosis type II (Hunter syndrome): clinical picture and treatment. Curr Pharm Biotechnol 2011;12:861-6.

24. Giugliani R, Villarreal ML, Valdez $C A$, et al. Guidelines for diagnosis and treatment of Hunter syndrome for clinicians in Latin America. Genet Mol Biol 2014;37:315-29.

25. Wraith J, Beck M, Giugliani R, et al. On Behalf Of The HOS Investigators. Initial report from the Hunter Outcome Survey. Genet Med 2008;10:508-16.

26. Young I, Harper P, Newcombe R, Archer I. A clinical and genetic study of Hunter's syndrome. 2 differences between mild and severe forms. J Med Genet 1982;19:408-11.

27. Arn P, Bruce IA, Wraith J, Travers H, Fallet S. Airway related symptoms and surgeries in patients with Mucopolysaccharidosis type I. Ann Otol Rhinol Laryngol 2015;124:198-205.

28. Ochiai $T$, Suzuki $Y$, Kato $T$, et al. Natural history of extensive Mongolian spots in MPS2 (Hunter syndrome): a survey among 52 Japanese patients. J Eur Acad Dermatol Venereol 2007;21:10825.

29. Musumeci ML, Lacarrubba F, Santagati C, Micali G. Multiple and superimposed Mongolian spots. BMJ Case Rep 2013;2013.

30. Gupta D, Thappa DM. Mongolian spots-how important are they? World J Clin Cases 2013;1:230-2.

31. Dvorakova L, Vlaskova H, Sarajlija A, et al. Genotype-phenotype correlation in 44 Czech, Slovak, Croatian and Serbian patients with mucopolysaccharidosis type II. Clin Genet 2017;91:787-96. 